\title{
Judicial Deference to Inconsistent Agency Statutory Interpretations
}

\section{Citation}

Yehonatan Givati \& Matthew Stephenson, Judicial Deference to Inconsistent Agency Statutory Interpretations, 40 J. Legal Stud. 85 (2011).

\section{Published Version}

$10.1086 / 658403$

\section{Permanent link}

http://nrs.harvard.edu/urn-3:HUL.InstRepos:10814612

\section{Terms of Use}

This article was downloaded from Harvard University's DASH repository, and is made available under the terms and conditions applicable to Open Access Policy Articles, as set forth at http:// nrs.harvard.edu/urn-3:HUL.InstRepos:dash.current.terms-of-use\#OAP

\section{Share Your Story}

The Harvard community has made this article openly available.

Please share how this access benefits you. Submit a story.

Accessibility 


\title{
CHICAGO JOURNALS
}

\section{The University of Chicago \\ The University of Chicago Law School}

\author{
Judicial Deference to Inconsistent Agency Statutory Interpretations \\ Author(s): Yehonatan Givati and Matthew C. Stephenson \\ Source: The Journal of Legal Studies, Vol. 40, No. 1 (January 2011), pp. 85-113 \\ Published by: The University of Chicago Press \\ Stable URL: http://www.jstor.org/stable/10.1086/658407 \\ Accessed: 01/06/2011 13:33
}

Your use of the JSTOR archive indicates your acceptance of JSTOR's Terms and Conditions of Use, available at http://www.jstor.org/page/info/about/policies/terms.jsp. JSTOR's Terms and Conditions of Use provides, in part, that unless you have obtained prior permission, you may not download an entire issue of a journal or multiple copies of articles, and you may use content in the JSTOR archive only for your personal, non-commercial use.

Please contact the publisher regarding any further use of this work. Publisher contact information may be obtained at http://www.jstor.org/action/showPublisher?publisherCode=ucpress.

Each copy of any part of a JSTOR transmission must contain the same copyright notice that appears on the screen or printed page of such transmission.

JSTOR is a not-for-profit service that helps scholars, researchers, and students discover, use, and build upon a wide range of content in a trusted digital archive. We use information technology and tools to increase productivity and facilitate new forms of scholarship. For more information about JSTOR, please contact support@jstor.org. 


\title{
Judicial Deference to Inconsistent Agency Statutory Interpretations
}

\author{
Yehonatan Givati and Matthew C. Stephenson
}

\begin{abstract}
Although administrative law doctrine requires courts to defer to an agency's reasonable statutory interpretation, the doctrine is unclear as to whether an agency gets less deference when it changes its own prior interpretation. We formally analyze how judicial deference to revised agency interpretations affects the ideological content of agencies' interpretations. We find a nonmonotonic relationship between judicial deference to inconsistent agency interpretations and interpretive extremism. This relationship arises because as courts become less deferential to revised interpretations, the initial agency finds it more attractive to promulgate a moderate interpretation that will not be revised. However, the less deferential the courts, the more extreme this moderate interpretation becomes. Normatively, our results suggest that an interest in responsiveness of interpretive policy to the preferences of the incumbent leadership favors deference to revised interpretations, whereas an interest in ideological moderation favors a somewhat less deferential posture to interpretive revisions.
\end{abstract}

\section{INTRODUCTION}

Federal agencies in the United States have a great deal of flexibility in interpreting the statutes that they administer. Although an agency may not contravene clear statutory directives, a reviewing court is supposed to defer to an agency's reasonable construction of an ambiguous statute,

Yehonatan givati is Postgraduate Fellow in Law and Economics, New York University School of Law, and Terence M. Considine Fellow in Law and Economics, Harvard Law School. MATTHEW C. STEPHENSON is Professor of Law, Harvard Law School. We are grateful to Louis Kaplow, Daryl Levinson, Eric Posner, and participants in workshops at Cornell Law School, the University of Texas Law School, and the Texas A\&M Department of Political Science, for helpful comments on earlier drafts, and the Terence M. Considine Fellowship and the John M. Olin Center for Law, Economics, and Business at Harvard Law School, for support of this research. 
even if the court believes that a different interpretation is superior. Put another way, the reviewing court's obligation is not to ascertain the best point estimate of statutory meaning but rather to define the bounds of a policy space from which the agency can select its preferred interpretation (Elliott 2005; Stephenson and Vermeule 2009). But what if the agency changes its interpretive position? Should courts be any less deferential to an agency interpretation that differs substantially from the agency's own prior interpretation, if the new interpretation would have been upheld as reasonable if it had been adopted in the first instance? Current doctrine is less clear regarding the answer to this question.

This article considers one aspect of this issue: whether, or under what conditions, reducing the degree of judicial deference to an inconsistent agency interpretation will lead an agency's interpretation to be more aggressive (that is, closer to the preferred position of the incumbent leadership) or more moderate (that is, closer to the midpoint between the ideal interpretations of the incumbent party and the opposition party). We consider both the agency's initial interpretive choice-when the agency is writing on a clean slate, with no prior agency interpretation-and the decision of the agency at a later time, when it is under the control of a different administration with different policy preferences. Our most important finding is that there is a nonmonotonic relationship between the degree of judicial deference to revised agency interpretations and the aggressiveness of the agency's initial interpretation. When courts are very likely to defer to a revised interpretation or are very likely to reject a revised interpretation, the agency's initial interpretation will strongly favor the interests of the incumbent administration, to the detriment of the party that is not in power. When the courts take a more intermediate approach-sometimes upholding revised interpretations but sometimes rejecting them-the agency's initial interpretation is more likely to be ideologically moderate.

The reason for this finding is as follows: although the incumbent party would like to secure the most favorable interpretation possible, it would also like to lock in its interpretation, thereby reducing the likelihood of future reversal. One way for the agency to protect itself from reversal is to issue a more moderate interpretation, so that a future administration does not find it worthwhile to bear the costs of revising it. If courts are generally unwilling to accept revised agency interpretations, however, the incumbent has little incentive to be moderate, because even an extreme interpretation is protected by the courts from administrative revision. Likewise, if the courts are very deferential to 
revised interpretations, the incumbent also has little incentive to be moderate, because the concessions that would be needed to preclude a future interpretive revision are too costly. The moderating strategy becomes attractive to the incumbent only when the courts are somewhat less deferential to inconsistent interpretations. In that case, the incumbent can lock in its interpretation by making modest but meaningful concessions on the substance.

The normative and doctrinal ramifications of this finding depend crucially on the specification of the social objective function. For example, one might believe that the appropriate normative objective is to maximize the correspondence between the agency's interpretation and the preferences of the incumbent administration, on the logic that the incumbent's preferences tend to track the preferences of a majority of voters. If so, one would prefer that courts defer just as much to a revised agency interpretation as to the original interpretation. On the other hand, one might believe that the median voter's ideal interpretation is usually somewhere between the ideal interpretations of the two dominant political parties. If so, a judiciary that is somewhat less deferential to a revised agency interpretation may be normatively desirable, because it can induce interpretive moderation under administrations of both parties. In short, normative assessment of deference doctrine depends in large part on whether it is more important to foster responsiveness to the ideology of the party in power or to encourage moderation between the views of the major political competitors.

This article is organized as follows. Section 2 provides a brief overview of extant legal doctrine and scholarly commentary on the question of whether courts should be less deferential to an agency interpretation that differs substantially from the agency's own prior interpretation. Section 3 develops a formal model that captures, in stylized form, how the judicial approach to this issue may affect the aggressiveness of agency interpretations, when the principal reason that an agency might wish to revise its interpretation is a shift in the agency's policy preferences. Section 4 assesses how variation in judicial doctrine on interpretative inconsistency affects agency behavior, and Section 5 considers the normative implications of these results. A brief conclusion follows.

\section{AGENCY INTERPRETIVE INCONSISTENCY: DOCTRINE AND COMMENTARY}

The starting point for any discussion of judicial deference to federal administrative agencies' statutory interpretations is the Supreme Court's 
seminal decision in Chevron v. Natural Resources Defense Council (467 U.S. 837 [1984]). The Chevron decision held that a reviewing court should defer to an agency's reasonable interpretation of a statute that the agency administers, even if the court would have interpreted the statute differently. However, the courts have sent mixed signals as to whether this strong form of deference applies in the same way when the agency's interpretation, although reasonable, differs from the agency's own prior interpretation. Chevron itself involved the Environmental Protection Agency's reversal of its earlier position on the meaning of the term "stationary source" in the Clean Air Act (42 U.S.C. secs. 75027503 [1977]), and the Chevron opinion indicated that a change in the agency's interpretive position is irrelevant to the appropriate level of judicial deference. Indeed, Justice John Paul Stevens' opinion for the Court emphasized that an "initial agency interpretation is not instantly carved in stone," since interpretive flexibility is an important aspect of agency authority (Chevron v. Natural Resources Defense Council, 467 U.S. at 863). However, only a few years later, in Immigration and Naturalization Service v. Cardoza-Fonseca (480 U.S. 421 [1987]), the Court (in an opinion also authored by Justice Stevens) declared that an "agency interpretation of a relevant provision which conflicts with the agency's earlier interpretation is 'entitled to considerably less deference' than a consistently held view" (480 U.S. at 446 [note 30]).

The tension between the positions taken in the Chevron decision and in the nearly contemporaneous Cardoza-Fonseca decision caused a great deal of uncertainty about whether interpretive inconsistency mattered under the Chevron framework. In Rust v. Sullivan (500 U.S. 173 [1991]), the Supreme Court seemed to come down squarely on the side of the original Chevron position: the Rust decision declared that an agency gets Chevron deference even if it reverses an earlier interpretation, emphasizing that Chevron itself involved just such a reversal (500 U.S. at 186). However, dicta in Pauley $v$. BethEnergy Mines (501 U.S. 680 [1991]), decided the same term as Rust, declared that "the case for judicial deference is less compelling with respect to agency positions that are inconsistent with previously held views" (501 U.S. at 698), and in Good Samaritan Hospital v. Shalala (508 U.S. 402 [1993]), the Court cited Cardoza-Fonseca for the proposition that "the consistency of an agency's position is a factor in assessing the weight that position is due" (508 U.S. at 417). The most recent word from the Supreme Court on this issue is National Cable \& Telecommunications Association v. Brand $X$ Internet Services (545 U.S. 967 [2005]). Brand X reaffirmed the ir- 
relevance of agency inconsistency, declaring that such inconsistency "is not a basis for declining to analyze the agency's interpretation under the Chevron framework" (545 U.S. at 981). However, the Court's history of inconsistency on this issue would give a savvy litigator reason to question whether an agency interpretation that reversed a prior interpretation would receive the same degree of deference as a more longstanding interpretation. ${ }^{1}$

In addition to these conflicting signals regarding the relevance of interpretive inconsistency under the Chevron framework, the Court's holding in United States $v$. Mead Corporation (533 U.S. 218 [2001]) made clear that some agency statutory interpretations-particularly those that appear in less formal guidance documents or interpretive statements, rather than rules or orders-would not be analyzed under Chevron at all, but instead would be reviewed pursuant to the less deferential standard articulated in Skidmore v. Swift \& Co. (323 U.S. 134 [1944]). Under Skidmore, a reviewing court is supposed to "respect" an agency's view, but the weight accorded to the agency's interpretation depends on a variety of factors, including "consistency with [the agency's own] earlier and later pronouncements" (323 U.S. at 140). This suggests that even if an agency does receive full Chevron deference for a changed interpretation if that interpretation is issued in a rule making or a formal adjudication, if the agency opts to issue the interpretation in a less formal context, the lack of consistency may result in less judicial deference. Just how much this factor matters, however, remains unclear. ${ }^{2}$ Relatedly, some lower courts (most notably the D.C. circuit) have embraced a doctrinal framework that allows agencies to announce certain statutory interpretations in "interpretive rules" (adopted without cumbersome notice-and-comment rule-making procedures) but requires any revision

1. Gossett (1997) reports that, notwithstanding the inconsistent rhetoric about whether inconsistent agency interpretations are entitled to less deference, in practice federal appeals courts do not seem to defer substantially less often to changed agency interpretations. If accurate, this evidence suggests that the position advanced in cases like Chevron, Rust, and Brand $X$ better captures the approach taken by most courts than does the contrary language in cases like Cardoza-Fonseca, Pauley, and Good Samaritan Hospital. Still, using court decisions to measure the level of deference to revised agency interpretation may be an imprecise method, since a lower level of deference may result in more moderate interpretations that will not be brought before a court (Givati 2010).

2. In one of the few attempts to assess this issue systematically, Hickman and Krueger (2007) report that although federal appeals court cases applying the Skidmore standard consider agency inconsistency, and although they do sometimes appear less deferential to inconsistent agency interpretations, agency consistency seems less important overall than the other factors that Skidmore identifies as relevant. 
to such interpretations to go through the full notice-and-comment process. ${ }^{3}$ For a certain subset of agency statutory interpretations, this makes revision of a prior statutory interpretation more difficult than the initial decision to promulgate that interpretation.

Although the focus here is on judicial review of agency statutory interpretations, it is worth observing that a similar issue arises in the more general context of judicial review of agency decisions for arbitrariness. In Motor Vehicle Manufacturers Association v. State Farm Mutual Automobile Insurance Company (463 U.S. 29 [1983]), the Supreme Court rejected the argument that an agency's decision to rescind a policy should be reviewed more deferentially than a decision to promulgate a new policy. According to State Farm, both the decision to promulgate a rule and the decision to rescind that rule are subject to a similar form of deferential, but nonetheless searching, "hard-look" review. State Farm, however, seemed to leave open the question of whether an agency's decision to change its earlier policy should be subject to more rigorous scrutiny, and some lower courts expressly adopted that position. ${ }^{4}$ In its recent decision in Federal Communications Commission v. Fox Television Stations (129 S.Ct. 1800 [2009]), the Supreme Court rejected the position that a change in agency policy is per se a reason for less deferential judicial review, but a close reading of Fox Television suggests that, as in the case of inconsistent agency statutory interpretations, the Court may have left itself room to review changed agency policy more aggressively in some circumstances. ${ }^{5}$ Although the contexts are similar, for the sake of clarity and to avoid some additional com-

3. See, for example, Alaska Professional Hunters Association v. Federal Aviation Administration (177 F.3d 1030 [D.C. Cir. 1999]) and Paralyzed Veterans of America v. D.C. Arena, L.P. (117 F.3d 579 [D.C. Cir. 1997]).

4. See, for example, Office of Communication of United Church of Christ v. Federal Communications Commission (707 F.2d 1413, 1425 [D.C. Cir. 1983]), and National Association for the Advancement of Colored People v. Federal Communications Commission (682 F.2d 993, 998 [D.C. Cir. 1982]).

5. In particular, although Justice Antonin Scalia's majority opinion in Fox Television declares that the statutory standard of review makes "no distinction . . . between initial agency action and subsequent agency action undoing or revising that action," his opinion also recognizes that there are some circumstances when an agency must "provide a more detailed justification than what would suffice for a new policy created on a blank slate"-for example, when the agency's "new policy rests upon factual findings that contradict those which underlay its prior policy; or when its prior policy has engendered serious reliance interests that must be taken into account" (129 S.Ct. at 1811). Justice Anthony Kennedy, whose vote was necessary to secure the 5-4 majority in the case, also stressed in a separate concurrence that a change in policy may sometimes entail additional explanatory burdens (129 S.Ct. at 1822) (Justice Kennedy concurring in part and concurring in the judgment). 
plications that arise in the context of State Farm-style hard-look review, we focus here on inconsistency in agency statutory interpretation, although many of our main findings would likely carry over to the State Farm context as well.

The question whether courts ought to defer less to agency statutory interpretations that are inconsistent with the agency's own prior interpretations has provoked debate among administrative law scholars. Many of these scholars conclude that the need for agencies to respond flexibly to changing circumstances militates in favor of deferring just as much to revised agency interpretations as to initial agency interpretations (Diver 1985; Sunstein 1990; Weaver 1992; Gossett 1997; Shuren 2001; Dotan 2005). A powerful additional argument for this position invokes the importance of political accountability: changes in an agency's interpretive position may reflect changes in the agency's political priorities—often triggered by a change in the presidential administration-and courts should respect this legitimate rationale for policy change (Pierce 1988; Scalia 1989; Sunstein 1990; Gossett 1997). The principal countervailing consideration noted in the literature is the rule-of-law interest in predictability and consistency in the meaning of statutes (Sunstein 1990; Merrill 1992; Murphy 2005). Another concern is that a policymotivated change in interpretation might reflect not a legitimate policy disagreement but rather an unjustified political hostility to an earlier regulatory program (Weaver 1992). For these reasons, some scholars have suggested that courts should be less deferential to revised agency interpretations (Sunstein 1990; Merrill 1992) or at least that courts should impose special additional explanatory or procedural burdens on agencies when such inconsistency occurs (Diver 1985; Sunstein 1990; Merrill 1992; Weaver 1992). In a similar spirit, Murphy (2005) argues that a revised interpretation should receive substantial deference only when the agency's initial interpretation was issued in a procedural context that makes it difficult to reverse.

Interestingly, in focusing on the trade-off between flexibility values and rule-of-law values, the extant literature has focused less on how the expected level of judicial deference to changed agency administration affects the content-in particular, the ideological slant-of agency interpretations. Much of the literature implicitly seems to presume that the content of an agency's interpretive choices-in particular, the initial choice-will look essentially the same, regardless of the judicial doctrine on deference to revised interpretations. However, a rich cognate literature in political economy suggests that the substantive choices of agencies 
(or other political actors) may depend crucially on strategic calculations regarding the insulation of their decisions from future reversal (McCubbins, Noll, and Weingast 1987, 1989; Moe 1989, 1990; De Figueiredo 2002; Stephenson 2003; Givati 2010). The administrative law literature has similarly noted in other contexts how current administrations may strive to insulate their decisions from future reversal (Beermann 2003; Mendelson 2003; O’Connell 2008). Perhaps, then, judicial doctrine on deference to inconsistent agency interpretations-which, after all, affects agencies' ability to insulate their policy choices from subsequent reversal-might have important and nonobvious effects on the substantive content of these interpretations. We explore this issue using the stylized formal model developed in the next section.

\section{THE MODEL}

\subsection{Primitives}

Consider a simple model with two periods, $t \in\{1,2\}$; two strategic players-a conservative party $(\mathrm{C})$ and a liberal party $(\mathrm{L})$; and one nonstrategic player, the judiciary. In each period, one of the two parties controls the presidency and therefore controls the interpretive decisions of an administrative agency charged with implementing some congressional statute. (For simplicity, we take the content of the statute as fixed and exogenous.) The interpretation chosen in period $t$ is $x_{t} \in \mathbb{R}$.

In the first period, without loss of generality, the conservative party is in power and can choose interpretation $x_{1}$. In the second period, the liberal party is in power. (In other words, the second period is defined as the point at which the liberal party takes power. $)^{6}$ The agency, once under liberal control, must decide whether to revise its interpretation of the statute; formally, the liberal administration chooses $x_{2}$. If the liberal agency does not revise the interpretation, then the first-period interpretation selected by the conservative administration applies in the second period $\left(x_{2}=x_{1}\right)$. If the liberal agency does revise its interpretation by selecting some $x_{2} \neq x_{1}$, then that interpretation, if upheld, prevails in the second period. If the liberal agency chooses to revise the prevailing interpretation, it also pays some fixed cost $k \in(0,1 /[1+\delta(1-\beta)])$, which can be interpreted as including the procedural costs of issuing a new

6. For simplicity, we assume that the conservative party's choice of $x_{1}$ does not affect the likelihood or timing of a transition in power, an assumption that seems reasonable for the vast majority of interpretive policy decisions. 
interpretation of the statute, the political cost of reopening a contentious political issue, and the expected litigation costs of defending the revision in court. ${ }^{7}$

Define the interpretation that prevails in period $t$ as $\tilde{x}_{t} \in \mathbb{R}$. The conservative party's ideal interpretation is $x_{\mathrm{C}} \leq 0$, and its utility in the first period is $u_{\mathrm{C}}\left(x_{1}\right)=-\left|\tilde{x}_{1}-x_{\mathrm{C}}\right|$. In the second period, the conservative party's utility is $u_{\mathrm{C}}\left(x_{2}\right)=-\left|\tilde{x}_{2}-x_{\mathrm{C}}\right|$ if the liberal party does not revise the conservative parties' interpretation, and it is $u_{\mathrm{C}}\left(x_{2}\right)=-\mid \tilde{x}_{2}-$ $x_{\mathrm{C}} \mid+\beta k$ if the liberal party does revise the statutory interpretation, where the parameter $\beta \in[0,1]$ captures the possibility that the conservative party may benefit from the liberal agency's diversion of resources to revision of the prior conservative interpretation. ${ }^{8}$ The liberal party's ideal interpretation is $x_{\mathrm{L}} \geq 1$, and its policy utility in period $t$ is $u_{\mathrm{L}}\left(x_{t}\right)=-\left|\tilde{x}_{t}-x_{\mathrm{L}}\right|$. In the first period, both parties discount the expected second-period payoff by $\delta \in[0,1]$. This parameter reflects how much each party cares about its future utility relative to its present utility, as well as how long each party expects the current period to last.

The agency's first-period interpretative decision is subject to judicial review. The judiciary, applying something like the Chevron doctrine, upholds any $x_{1} \in[0,1]$. That is, the $[0,1]$ interval is the policy space that the statutory ambiguity opens up for the agency; $x_{1}=0$ is the most conservative interpretation that the court would uphold, whereas $x_{1}=1$ is the most liberal interpretation that the court would uphold. ${ }^{9}$ In the second period, if the liberal agency does not revise the prevailing interpretation, then there is no judicial review. If, however, the liberal agency chooses a new interpretation of the statute, $x_{2} \neq x_{1}$, that choice is again subject to judicial review. In the second period, as in the first, the judiciary will invalidate any interpretive choice outside the $[0,1]$ interval. Furthermore, the judiciary might be less deferential to incon-

7. The upper bound on $k$ guarantees that there are values of the other parameters such that the liberal agency will sometimes be willing to revise a previous interpretation.

8. Although we include, for completeness, the $\beta k$ term in the conservative party's utility function, our main qualitative results are unaffected by $\beta$, so long as $\beta$ is not too large. We also note that our interpretation of $k$ and $\beta$ suggests the possibility of even more complex strategic behavior, in which the conservative and liberal administrations both have to select which among a large set of possible issues they will choose to address. We defer these complications to future research.

9. If the judiciary were to reject the agency's first-period interpretation, the court would select some alternative interpretation $x_{1}=q \in[0,1]$. In our model, this never occurs in equilibrium, because the conservative agency is always weakly better off selecting some $x_{1} \in[0,1]$. 
sistent agency interpretations. We model this by assuming that, even if the liberal agency selects some $x_{2} \in[0,1]$, nonetheless if $x_{2} \neq x_{1}$, there is some probability, $\alpha \in[0,1]$, that the judiciary will reject the agency's new interpretation. If the judiciary does so, the first-period interpretation prevails in the second period $\left(\tilde{x}_{2}=x_{1}\right) \cdot{ }^{10}$

The parameter $\alpha$ therefore captures the effective legal doctrine regarding judicial deference to revised administrative interpretations. ${ }^{11}$ Greater values of $\alpha$ indicate a lower likelihood that the judiciary will uphold an agency interpretation that is inconsistent with the agency's prior views. If $\alpha=0$, then inconsistency makes no difference whatsoever-as cases like Rust, Brand X, and Chevron itself suggest ought to be the rule. A value of $\alpha=1$ would represent the (unrealistic) extreme case in which the agency's initial interpretation is indeed "carved in stone" and cannot be revised by the agency, absent congressional amendment of the statute. Values of $\alpha$ between zero and one indicate an intermediate position, such as that suggested by cases like CardozaFonseca and Good Samaritan Hospital, as well as the Skidmore standard: inconsistency increases the chances that the reviewing court will reject the agency's interpretation, but it does not guarantee it.

Our principal analysis assumes that $\alpha$ is constant-that is, the prob-

10. We are agnostic (at least for purposes of this article) as to judicial motivations in reviewing agency interpretations of statutes, a topic on which there is a great deal of debate (Cohen and Spitzer 1994, 1996; Revesz 1997; Cross and Tiller 1998; Stephenson 2004; Miles and Sunstein 2006; Richards, Smith, and Kritzer 2006; Smith 2007). That said, we do assume that whatever the judges' underlying motivations, in practice they behave as if there is a defined "zone of discretion" from which the agency may select an initial interpretation. This assumption entails some loss of generality, insofar as it excludes the possibility, discussed in other theoretical work, that each agency's effective zone of discretion may vary depending on the correspondence between judicial and agency preferences (Spiller 1992; Cohen and Spitzer 1994, 1996; Stephenson 2006b). Nonetheless, we think it is reasonable, at least as a first cut, to model the judiciary as a consistent and faithful applier of a standard deference doctrine, such that the discretionary zone is constant. This assumption can and should be relaxed in future work. We also note that we assume that, whatever the judges' underlying motivations, the acceptable range of interpretations is constant across both periods. This is obviously a simplification; indeed, one way that the incumbent party in the first period might try to insulate its interpretive decisions is by appointing judges who would reject revisions on the merits. We bracket this possibility, as we bracket the possibility that the legislature might amend the statute, to simplify the exposition, in order to focus on other dynamics.

11. Our assumption that nondeference to changed interpretations can be modeled as a probability of rejecting an interpretation that falls within the discretionary zone can be thought of either as reflecting the unpredictable views of individual judges with respect to whether revised interpretations are entitled to deference or as reflecting heterogeneity across the population of potential (randomly assigned) judges with respect to this issue. 
ability of the court rejecting a revised interpretation does not depend on the ideological content of that interpretation. It is plausible, however, that a court might be more likely to reject an agency interpretation that represents a substantial change from the prior interpretation than to reject a more marginal interpretive revision. That alternative assumption would imply that $\alpha$ is an increasing function of $\left|x_{2}-x_{1}\right|$. That alternative assumption, however, adds substantial complexity to the analysis; therefore, to build intuition, the main text focuses on the case where $\alpha$ is constant. We show in Appendix A that all the main qualitative results of our analysis hold in the case where $\alpha$ is an increasing function of $\left|x_{2}-x_{1}\right|$, provided that one is willing to make simple and, in our view, substantively reasonable assumptions about the functional form of $\alpha\left(\left|x_{2}-x_{1}\right|\right)$.

\subsection{Equilibrium}

We find the equilibrium of the game by backward induction. For simplicity, and without loss of generality, we assume that $x_{\mathrm{C}}=0$ and $x_{\mathrm{L}}=1$. (If either party had more extreme preferences-that is, if $x_{\mathrm{C}}<$ 0 or $x_{\mathrm{L}}>1$, then that party would always suffer some additional utility loss even if it achieved its most-favored judicially acceptable interpretation. This would affect that party's overall utility level, but not its equilibrium strategy.) In the second period, if the liberal agency decides to incur the cost $k$ and revise the interpretation that was chosen in the first period $\left(x_{1}\right)$, the liberal agency would choose whatever new interpretation $\left(x_{2}\right)$ maximizes its expected second-period utility. That is, the liberal agency chooses $x_{2}$ to maximize

$$
\mathrm{EU}_{\mathrm{L}}^{\text {period2 }}(\text { revise })=-(1-\alpha)\left(1-x_{2}\right)-\alpha\left(1-x_{1}\right)-k \text {. }
$$

From this, it follows immediately that a liberal agency that chooses to revise the interpretation of the statute would choose $x_{2}=1$. So, the liberal agency's expected second-period utility from attempting to revise the interpretation of the statute is $-\alpha\left(1-x_{1}\right)-k$. If, on the other hand, the liberal agency chooses to accept the prevailing first-period interpretation without attempting any revision, then its second-period utility is as follows:

$$
U_{\mathrm{L}}^{\text {period2 }}(\text { accept })=-\left(1-x_{1}\right) .
$$

The liberal agency will choose to revise the existing statutory interpretation only if the expected second-period utility resulting from doing so is positive. This calculation will take into account both the likely result-whether the judiciary upholds the new interpretation-and the 
cost, $k$, of attempting an interpretive revision. Formally, the liberal agency will promulgate an alternative interpretation of the statute if and only if expression (1) is greater than expression (2). That is, the liberal agency will attempt to revise the interpretation of the statute if and only if

$$
x_{1}<\left(1-\frac{k}{1-\alpha}\right) \equiv x^{\mathrm{T}}
$$

The value $x^{\mathrm{T}}$ can be interpreted as a threshold value: it is the most conservative first-period interpretation that would not trigger an attempted reversal by the liberal agency in the second period.

Now consider the conservative agency's choice. The conservative agency can lock in its interpretation for both periods if it chooses a firstperiod interpretation $x_{1} \geq x^{\mathrm{T}}$, because, as we know from expression (3), the liberal agency would not attempt to revise an interpretation in that range. The conservative agency's utility from locking in interpretation $x_{1}$ for both periods is

$$
U_{\mathrm{C}}(\text { lock in })=-(1+\delta) x_{1} .
$$

This expression is decreasing in $x_{1}$, so the conservative agency's mostpreferred $x_{1}$ in the $x_{1} \in\left[x^{\mathrm{T}}, 1\right]$ range is $x^{\mathrm{T}}$. This is intuitive: $x^{\mathrm{T}}$ is sufficiently moderate that the liberal agency would accept it in the second period, and the conservative agency has no reason to make additional concessions by choosing a more liberal interpretation.

If the conservative agency were to choose a first-period interpretation $x_{1}<x^{\mathrm{T}}$, then the liberal agency would attempt a second-period reversal. Accordingly, the conservative agency's expected utility from this more risky interpretive choice is

$$
\mathrm{EU}_{\mathrm{C}}(\text { risky })=-(1+\delta \alpha) x_{1}-\delta(1-\alpha)+\delta \beta k .
$$

This expression is also decreasing in $x_{1}$, which implies that if the conservative agency were to choose an $x_{1}<x^{\mathrm{T}}$, it would choose $x_{1}=0$.

We have shown that the conservative agency's optimal risky interpretation is $x_{1}=0$, and the optimal interpretation that the conservative agency can lock in for both periods is $x_{1}=x^{\mathrm{T}}$. All that remains is to compare the expected utilities of these two approaches. Substituting these optimal values into expressions (4) and (5) allows us to establish the condition under which the conservative agency will (weakly) prefer the lock-in approach to the risky approach. That condition is

$$
x^{\mathrm{T}} \leq \frac{\delta(1-\alpha-\beta k)}{1+\delta} .
$$


Intuitively, if $x^{\mathrm{T}}$ is close enough to the conservative agency's ideal point $\left(x_{\mathrm{C}}=0\right)$, the conservative agency will choose $x_{1}=x^{\mathrm{T}}$ over $x_{1}=0$. Expression (6) implies that any interpretation that the conservative agency is both willing and able to lock in for both periods must be weakly less than one-half. (In addition, note that the more the conservative party benefits from the liberal agency's effort cost-the greater the value of $\beta$-the more likely it is that the conservative agency will prefer the risky approach to the lock-in approach; if $\beta k \geq(1-a)$, then there is no $x^{\mathrm{T}}$ sufficiently low for the conservative agency to pursue the lock-in approach.) For expositional convenience, we can substitute the expression for $x^{\mathrm{T}}$ from expression (3), to rewrite the condition in expression (6) as

$$
Z \equiv(1-\alpha)(1+\delta \alpha)-k[1+\delta-(1-\alpha) \delta \beta] \leq 0 .
$$

The conservative agency's optimal first-period interpretation, $x_{1}^{*}$, is therefore

$$
x_{1}^{*}=\left\{\begin{array}{ll}
0 & \text { if } Z>0 \\
x^{\mathrm{T}} & \text { if } Z \leq 0
\end{array} .\right.
$$

The expected second-period decision depends on whether the conservative agency opts for the lock-in approach or the risky approach. If the former, then the second-period interpretation is simply $x^{T}$. If the latter, then the second-period interpretation is either 1 (if the judiciary accepts the liberal agency's revision) or 0 (if the judiciary rejects the new interpretation on grounds of inconsistency). This means that in equilibrium the expected value of the interpretation that prevails, $\tilde{x}_{2}$, is

$$
E\left(\tilde{x}_{2}\right)=\left\{\begin{array}{ll}
1-\alpha & \text { if } Z>0 \\
x^{\mathrm{T}} & \text { if } Z \leq 0
\end{array} .\right.
$$

\section{ANALYSIS}

We are interested principally in how $\alpha$, the probability that the judiciary reverses an agency interpretation (which we will call "inconsistency doctrine”), affects the agency's interpretive choice. Inconsistency doctrine affects interpretive choice in two ways. First, if the conservative agency chooses the lock-in approach, it follows from expression (3) that inconsistency doctrine will affect how aggressive the lock-in interpretation will be. Second, from expressions (7) and (8), it is apparent that inconsistency doctrine will influence the conservative agency's decision whether to lock in its interpretation or to take a riskier interpretive approach that will provoke a future liberal agency to attempt reversal.

On the first point, regarding the aggressiveness of the conservative 
agency's interpretation if the agency opts for the lock-in approach, an increase in the probability that the judiciary will reject an inconsistent agency interpretation makes the optimal lock-in approach more conservative. Formally,

$$
\frac{\partial x^{\mathrm{T}}}{\partial \alpha}=-\frac{k}{(1-\alpha)^{2}}<0
$$

The intuition here is straightforward. As the judiciary becomes less likely to accept a revised interpretation, attempting such a revision becomes less appealing to the liberal agency in the second period; if the judiciary rejects the attempted revision, the liberal agency will have incurred the cost $k$ for no benefit. Therefore, the conservative agency does not need to concede as much in the first period to lock in its interpretation-it can adopt a more aggressively conservative interpretation without provoking the liberal agency to attempt reversal.

On the second point, regarding the conservative agency's choice of interpretative strategy, the lock-in approach becomes more appealing as the probability that the judiciary rejects an inconsistent interpretation increases. Formally,

$$
\frac{\partial Z}{\partial \alpha}=\delta-2 \alpha \delta-1-\delta \beta k \leq 0
$$

The intuition for this follows immediately from the fact that increasing the judiciary's probability of rejecting an inconsistent agency interpretation allows the conservative agency to lock in an even more aggressive interpretation without risking reversal.

We have established that decreasing judicial deference to inconsistent agency interpretations both increases the appeal of the lock-in approach and makes the lock-in approach more aggressive. The lock-in approach, however, is (weakly) less aggressive than the risky approach. Therefore, decreasing judicial deference to inconsistent agency interpretations may increase or decrease the aggressiveness of the conservative agency's firstperiod interpretation.

To illustrate, consider the effect of a change in judicial doctrine from $\alpha_{\text {low }}$ to $\alpha_{\text {high }}$ (where $\alpha_{\text {high }}>\alpha_{\text {low }}$ ). Let us further define $\alpha^{\mathrm{T}}$ as the value of $\alpha$ for which the condition in expression (7) holds with equality (that is, $\alpha^{\mathrm{T}}$ is the minimum value of $\alpha$ that induces the conservative agency to choose the lock-in approach). If the conservative agency adopts the lockin approach both before and after the change in $\alpha$ (that is, $\alpha_{\text {low }}>\alpha^{\mathrm{T}}$ ), the increase in $\alpha$ will cause the agency to adopt a more aggressively 
conservative interpretation in the first period. ${ }^{12}$ If the conservative agency adopts the risky approach both before and after the change (that is, $\alpha_{\text {high }}<\alpha^{\mathrm{T}}$ ), the increase in $\alpha$ will make no difference to the conservative agency's first-period choice. If, however, the increase in $\alpha$ induces the conservative agency to switch from the risky approach to the lock-in approach (that is, $\alpha_{\text {high }}>\alpha^{\mathrm{T}}>\alpha_{\text {low }}$ ), then the increase in $\alpha$ will lead the conservative agency to adopt a less aggressive first-period interpretation, because the conservative agency's most-preferred lock-in interpretation is more liberal than its most-preferred risky interpretation.

This is the key positive implication of our analysis: the relationship between the level of judicial hostility to inconsistent agency interpretations $(\alpha)$ and the aggressiveness of the first-period interpretation $\left(x_{1}^{*}\right)$ is nonmonotonic. When the judiciary is as deferential to a revised interpretation as to an initial interpretation $(\alpha=0)$, the conservative agency selects the most conservative permissible interpretation $\left(x_{1}^{*}=\right.$ $0)$, and the liberal agency always successfully replaces it with the most liberal permissible interpretation $\left(x_{2}^{*}=1\right)$. As $\alpha$ increases from 0 to $\alpha^{\mathrm{T}}$, the conservative agency continues to select the most conservative permissible interpretation $\left(x_{1}^{*}=0\right)$; the liberal agency continues to attempt to change the interpretation to the most liberal interpretation permissible, but there is now a positive probability that the court will reject that attempt (implying that $x_{2}=1$ with probability $1-\alpha$ and $x_{2}=0$ with probability $\alpha$ ). Once $\alpha=\alpha^{T}$, the conservative agency switches from the risky approach to the lock-in approach, which leads to a more moderate first-period interpretation $\left(x_{1}^{*}=1-[k /(1-\alpha)]>\right.$ $0)$; this interpretation persists in the second period as well, because the liberal agency no longer finds it worthwhile to attempt reversal. Further increases in $\alpha$, however, allow the conservative agency to lock in moreconservative interpretations. Once $\alpha=1-k$, the conservative agency again chooses $x_{1}^{*}=0$, and this interpretation will stick in both periods. This pattern is illustrated in Figure 1.

Although our main focus concerns changes in $\alpha$, it is also interesting to consider the impact of changes in $k$, the fixed cost to the liberal agency of attempting an interpretive revision. After all, as noted in Section 2, a number of scholars and judicial opinions have suggested that the correct approach for dealing with revised agency interpretations is not to reduce the probability of deferring to such revisions but rather to impose

12. This statement relies on the assumption that $\alpha_{\text {low }}<1-k$. 


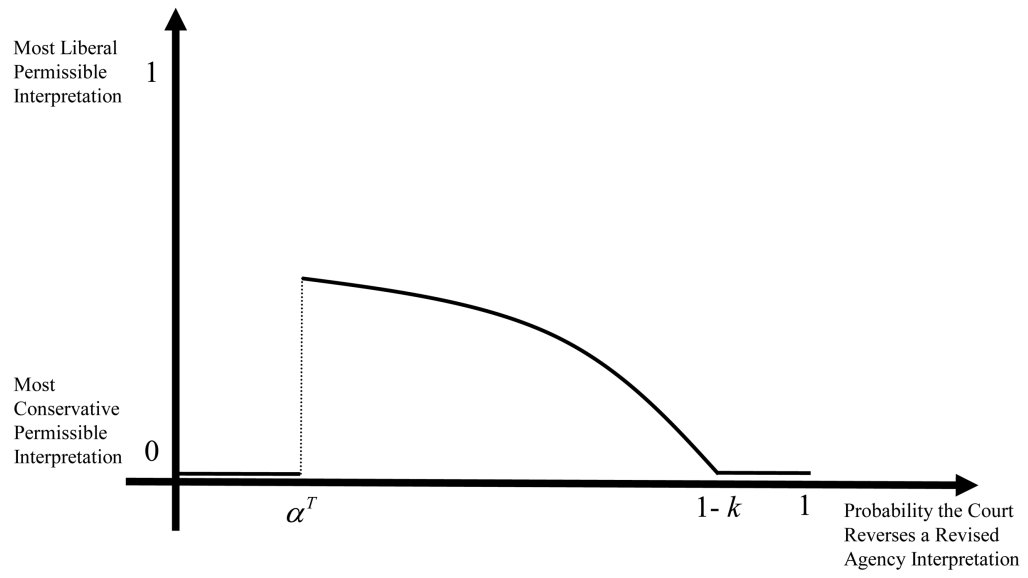

Figure 1. The conservative agency's statutory interpretation

additional explanatory or procedural costs on agencies when those agencies want to change their prior interpretive position. It turns out that the results for changes in $k$ are qualitatively similar to the results shown above for changes in $\alpha$. Formally,

$$
\frac{\partial x^{T}}{\partial k}=-\frac{1}{1-\alpha}<0
$$

and

$$
\frac{\partial Z}{\partial k}=-[1+\delta-(1-\alpha) \delta \beta]<0
$$

This implies that as the fixed cost to the agency of revising a previous interpretive decision increases, the first-period agency can lock in a more aggressive interpretation, and the attractiveness of this lock-in strategy to the first-period agency increases as a result. This leads to an analogous nonmonotonicity result: increasing the fixed cost of revisiting a prior agency interpretation may lead to a more moderate initial interpretation, if this increase causes the first-period agency to switch from the risky approach to the lock-in approach; however, further increases in this fixed cost will cause the first-period interpretation to become progressively more extreme. 


\section{NORMATIVE IMPLICATIONS}

Section 4 considered, as a positive matter, how inconsistency doctrine affects the ideological extremism of agency interpretations. What are the normative implications, if any, of this analysis? A full normative discussion would be a complex enterprise well beyond the scope of this article. As a preliminary contribution to this larger endeavor, we consider two normative benchmarks: the welfare of the two political parties and the welfare of a hypothetical median voter (whom we will refer to simply as the "voter").

\subsection{Parties' Welfare}

Decreasing deference to revised agency interpretations always makes the conservative agency better off. ${ }^{13}$ What about the liberal agency? If the conservative agency chooses the risky approach in the first period, the liberal agency will choose $x_{2}^{*}=1$ in the second period, giving the liberal agency the following total utility:

$$
E U_{L}(\text { risky })=-(1+\delta \alpha+k) .
$$

If, on the other hand, the conservative agency adopts the lock-in approach in the first period setting $x_{1}^{*}=x^{T}$, the liberal agency will not alter this interpretation in the second period. This means that the liberal agency's total utility will be

$$
U_{\mathrm{L}}(\text { lock in })=-(1+\delta)\left(1-x^{\mathrm{T}}\right)=\frac{-(1+\delta) k}{1-\alpha} .
$$

Note that the liberal agency's expected utility from the conservative agency's choice of the risky approach and the lock-in approach both decrease as the judiciary becomes less deferential to revised agency interpretations (that is, as $\alpha$ increases). However, this does not mean that decreasing deference to revised agency interpretations always decreases the liberal agency's utility. To see this formally, define $\tilde{\alpha}^{\mathrm{T}}=\alpha^{\mathrm{T}}-$ $k[(1-\delta \beta) / \delta] .{ }^{14}$ For any $\alpha^{\prime} \in\left[\tilde{\alpha}^{\mathrm{T}}, \alpha^{\mathrm{T}}\right]$, we can define $\alpha^{\prime \prime}>\alpha^{\mathrm{T}}$ such that the liberal agency would prefer any $\alpha \in\left[\alpha^{\mathrm{T}}, \alpha^{\prime \prime}\right]$ to $\alpha^{\prime}$, although $\alpha>$ $\alpha^{\prime} .{ }^{15}$ This result is illustrated in Figure 2 .

In Figure 2, we see two functions. The linear function represents the

13. This follows from the fact that $\mathrm{EU}_{\mathrm{C}}$ (risky) $=-\delta(1-\alpha)+\delta \beta k$ and $U_{\mathrm{C}}$ (lock in) $=$ $-(1+\delta)[1-k /(1-\alpha)]$ are both increasing in $\alpha$, and the conservative agency always chooses the higher of the two.

14. The value $\tilde{\alpha}^{\mathrm{T}}$ is defined such that $\mathrm{EU}_{\mathrm{L}}\left(\right.$ risky, $\left.\tilde{\alpha}^{\mathrm{T}}\right)=U_{\mathrm{L}}\left(\right.$ lock in, $\left.\alpha^{\mathrm{T}}\right)$. See Appendix $\mathrm{B}$.

15. The value $\alpha^{\prime \prime}$ is defined such that $\mathrm{EU}_{\mathrm{L}}\left(\right.$ risky, $\left.\alpha^{\prime}\right)=U_{\mathrm{L}}\left(\operatorname{lock}\right.$ in, $\left.\alpha^{\prime \prime}\right)$. Formally, $\alpha^{\prime \prime}=$ $1-[(1+\delta) k] /\left(1+\delta \alpha^{\prime}+k\right)$. See Appendix B. 


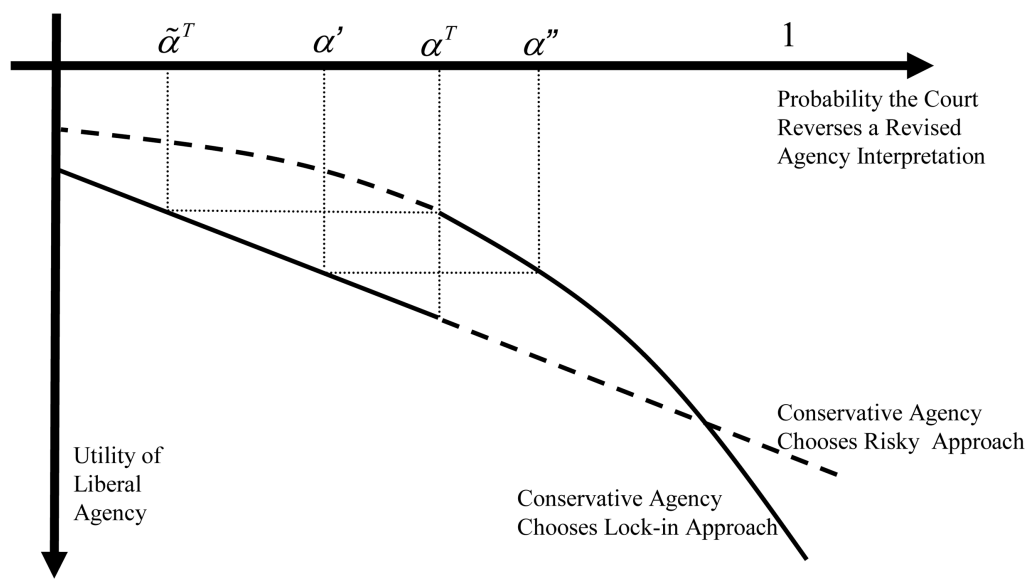

Figure 2. The liberal agency's expected utility

liberal agency's utility when the conservative agency chooses the risky approach (expression [14]). The curve represents the liberal agency's utility when the conservative agency chooses the lock-in approach (expression [15]). The liberal agency's actual expected utility (represented by the bold line in Figure 2) is the linear function for $\alpha<\alpha^{\mathrm{T}}$ and the curve for $\alpha \geq \alpha^{\mathrm{T}}$, since at $\alpha^{\mathrm{T}}$ the conservative agency shifts from the risky approach to the lock-in approach. It is clear from Figure 2 that the liberal party's expected utility is higher at $\alpha \in\left[\alpha^{\mathrm{T}}, \alpha^{\prime \prime}\right]$ than at $\alpha^{\prime}$.

Intuitively, the conservative and liberal agencies have zero-sum preferences on the interpretation of the statute. At $\alpha^{\mathrm{T}}$, the conservative agency moves from the risky approach to the lock-in approach, but its utility from both approaches is equal. However, moving to the lock-in approach increases the liberal agency's utility, since it does not have to bear the cost of revising the conservative agency's interpretation $(k)$. Thus, the liberal agency would benefit from a decrease in the deference to revised agency interpretations if (1) this decrease results in a shift from the risky approach to the lock-in approach, and (2) the savings resulting from avoiding the cost of revising the conservative agency's interpretation are greater than the decrease in utility from a more conservative interpretation. This analysis shows that decreasing the deference to revised agency interpretations could be a Pareto improvement for both the conservative and the liberal parties. 


\subsection{Median Voter Welfare}

That a moderate reduction in deference to revised agency interpretations can improve the welfare even of the party out of power in the first period may be normatively significant, but perhaps what would benefit the political parties is less important than what would benefit the citizenry. We therefore consider an alternative normative benchmark: the welfare of the median voter in the electorate. Median voter welfare is problematic as a normative standard, both because of the fact that the ideal policy of the median voter may not be the policy that maximizes aggregate social welfare (Stiglitz 2000), and because the majoritarianism implicit in catering to the median voter may be insufficiently sensitive to minority interests. ${ }^{16}$ Also, for multidimensional issues there may not be a single median voter, nor indeed any coherent way to describe what the "majority prefers" (Arrow 1951; Riker 1982; Shepsle 1992). Nonetheless, there are many situations in which the notion of accountability to electoral majorities is both conceptually coherent and normatively relevant, and under certain plausible assumptions, the majority-preferred policy may at least roughly approximate the welfare-maximizing policy. Furthermore, much administrative law doctrine proceeds on the assumption that responsiveness to electoral majorities is an important (although not necessarily the only) normative objective. For these reasons, we explore how inconsistency doctrine might affect median voter welfare. Formally, we define the voter's ideal point in the first period as $x_{v 1}$, and her ideal point in the second period as $x_{v 2}$. For simplicity, we assume that the voter has the same discount factor, $\delta$, as the political parties. The voter's welfare is therefore

$$
U_{V}=-\left|x_{v 1}-\tilde{x}_{1}\right|-\delta\left|x_{v 2}-\tilde{x}_{2}\right|,
$$

where $\tilde{x}_{t}$ is the interpretation that prevails in period $t$.

We explore two simplified conjectures about the relationship between the voter's ideal interpretation and the interpretation favored by the party currently in power. According to one interpretation, the voter's ideal point is equal to the ideal point of the incumbent party $\left(x_{v l}=0\right.$ and $x_{v 2}=1$ ). The assumption here is that the conservative party controls the agency in the first period because the voter in the first period has conservative preferences. The liberal party will take over when the

16. For these and other reasons, much economic analysis of legal rules uses aggregate social welfare, rather than majoritarianism, as the principal normative criterion (Kaplow and Shavell 2002; Listokin 2008). 
voter's preferences have shifted in a liberal direction. Under this assumption, the voter's expected utility is

$$
\mathrm{EU}_{v}=\left\{\begin{array}{ll}
-\delta \alpha & \text { if } Z>0 \\
-x^{\mathrm{T}}-\delta\left(1-x^{\mathrm{T}}\right) & \text { if } Z \leq 0
\end{array} .\right.
$$

It is apparent from expression (17) that the voter in this case is best off if the judiciary always accepts a revised interpretation $(\alpha=0) .{ }^{17}$ That is intuitive, because the voter is assumed to want whichever party is currently in power to implement its most-preferred interpretation. A judicial doctrine of $\alpha=0$ maximizes the responsiveness of agency interpretations to the views of the incumbent administration, which is what the voter would want if the incumbent's views reliably track the voter's own.

However, we might reasonably suppose that the administration's ideal point does not perfectly track the voter's ideal point. Indeed, it is plausible that a great deal of the difference between the preferred interpretations of liberal and conservative administrations is not due to shifts in voter preferences on that particular interpretive issue but rather is due to the influence of ideological extremists or parochial interest groups, or perhaps to the leadership's own policy agenda. This is especially likely because the voter does not elect each agency head independently but rather elects a single president with a bundle of policy positions (Berry and Gersen 2008). According to this view, the voter's ideal interpretation is likely to lie somewhere in between the ideal interpretations of the two parties (Stephenson 2008). For simplicity, let us suppose that the voter's ideal interpretation in both periods is midway between the ideal interpretations of the liberal and conservative parties-that is, $x_{v 1}=x_{v 2}=$ $1 / 2$. In this case, the voter's utility if the conservative agency adopts the lock-in approach is

$$
U_{\nu}(\text { lock in })=-(1+\delta)\left|\frac{1}{2}-x^{\mathrm{T}}\right| .
$$

The voter's expected utility if the conservative agency adopts the risky approach is

$$
\mathrm{EU}_{v}(\text { risky })=-(1+\delta)\left(\frac{1}{2}\right)
$$

It follows that the voter is weakly better off if the conservative agency chooses a lock-in approach. The reason is that, in this case, the voter is indifferent between the liberal and conservative parties' most-favored

17. Note that when $\alpha=0$, we get $Z>0$. 
interpretative approaches; the risky approach guarantees an extreme interpretation in both periods, which the voter dislikes. The lock-in approach, on the other hand, guarantees a more moderate interpretation in both periods. Therefore, the voter would always prefer $\alpha^{\mathrm{T}}$ to any $\alpha<\alpha^{\mathrm{T}}$. Furthermore, if $\alpha \geq \alpha^{\mathrm{T}}$, the voter's expected utility is decreasing in $\alpha$. This follows from the fact that $x^{\mathrm{T}}$ is decreasing in $\alpha$ and that $x^{\mathrm{T}} \leq 1 / 2$ for any $\alpha \geq \alpha^{\mathrm{T}}$. Therefore, when the voter's ideal interpretation is at the midpoint between the conservative and liberal parties' ideal interpretations, the voter would most prefer that the judiciary reject a changed agency interpretation with probability $\alpha^{\mathrm{T}}$, because this judicial doctrine maximizes the moderation of the agency's interpretation in both periods.

Both of the preceding normative analyses are clearly unrealistic, even if one restricts the inquiry to the median voter welfare. The former case supposes that the incumbent's ideal interpretation is perfectly correlated with the median voter's ideal interpretation, whereas the latter case supposes both that the incumbent's ideal interpretation is uncorrelated with the voter's ideal interpretation and that the voter's ideal is midway between that of the two political parties. However, these simple polar cases illustrate the considerations that would inform a more nuanced and realistic analysis, in which the median voter's ideal point is somewhere between the midpoint and the incumbent's ideal point. The tighter the correlation between voter preferences and the preferences of the incumbent party, the more the voter would prefer that courts defer to revised agency interpretations, because this approach maximizes interpretive responsiveness to the incumbent party's ideology. However, when agencies are likely to be more ideologically extreme than the median voter, some degree of judicial hostility to revised agency interpretations becomes more attractive. In our model, this is not because the voter has some intrinsic interest in interpretive consistency-although that might be a real consideration in some circumstances (Stephenson 2006a)-but rather because a reduction in deference to changed agency interpretations might induce greater interpretive moderation. Normative analysis must be attentive to how this aspect of judicial doctrine affects the trade-off between responsiveness and moderation in agency interpretation.

\section{CONCLUSION}

Modern administrative law doctrine has struggled with the question of the desirable degree of deference that a reviewing court ought to confer 
on an administrative agency's interpretation of a statute when the agency's interpretation differs from the agency's own prior construction of the same statutory provision. The appropriate resolution of this thorny doctrinal problem must take into account a number of factors beyond the scope of this article, including the need to respond to changed circumstances and the rule-of-law interest in administrative consistency. Nonetheless, any complete analysis must also consider how inconsistency doctrine affects the expected substantive ideological content of agency statutory interpretations. Our analysis has demonstrated that this relationship is more subtle and complicated than it might initially appear.

Most importantly, there is a nonmonotonic relationship between the probability that a court will accept a revised interpretation and the ideological extremism of the original interpretation. This occurs because the first agency to interpret a statute must choose between two approaches: it can take a risky approach, advancing an extreme interpretation that it can anticipate its political opponents will try to undo as soon as they take power, or it can "lock in" an interpretation that is sufficiently moderate that its political opponents would not bother trying to revise it, given the inherent costs of making such an attempt. When courts are less deferential to revised interpretations, the lock-in approach becomes more attractive because the original agency can secure an even more favorable interpretation without fear of attempted reversal. So, although decreasing deference to revised interpretations can sometimes make the original interpretation more extreme, such a decrease can make the original interpretation more moderate if it induces the initial agency to switch from the risky approach to the lock-in approach.

The normative ramifications of this positive observation depend crucially on the social objective function. If the goal is to increase the responsiveness of interpretive choices to the party currently in power-by the logic that electoral victory signifies representativeness of citizen preferences-then one would prefer that judicial deference to revised agency interpretations be no different than judicial deference to initial agency interpretations. If, however, one believes that political parties' interpretive preferences tend to be extreme relative to a majority of the electorate-that is, if the variance in the ideal points of political leaders over time tends to be much larger than the variance in the ideal point of the median voter over time-or if one is interested in advancing the joint welfare of the party in power and the party out of power, then a moderately lower level of deference to revised interpretations, or some- 
what greater fixed costs to an agency of revising a previous interpretation, can be welfare enhancing.

\section{APPENDIX A}

The analysis in the main text assumes that the judiciary's probability of rejecting the liberal agency's second-period interpretation is zero if $x_{2}=x_{1}$ and a positive constant, $\alpha$, if $x_{2} \neq x_{1}$. Here, we extend the analysis to consider the (arguably more realistic) setting in which the probability that the judiciary rejects the liberal agency's interpretation depends on how different the new interpretation $\left(x_{2}\right)$ is from the original one $\left(x_{1}\right)$. In other words, here we assume that $\alpha$ is an increasing function of $\left|x_{2}-x_{1}\right|$.

Solving this extension is quite difficult-and produces indeterminate results-unless one imposes additional functional form assumptions on $\alpha\left(\left|x_{2}-x_{1}\right|\right)$. Here, we assume that the function is linear: $\alpha\left(\mid x_{2}-\right.$ $\left.x_{1} \mid\right)=\gamma\left(x_{2}-x_{1}\right)$, where $\gamma \geq 0$. (Because the liberal agency would never adopt an $x_{2}<x_{1}$ in equilibrium, we can express the distance between $x_{2}$ and $x_{1}$ simply as $x_{2}-x_{1}$ rather than as $\left|x_{2}-x_{1}\right|$.) In this formulation, the coefficient $\gamma$ captures the degree to which a fixed level of inconsistency increases the probability of judicial reversal. Thus, in this extension, $\gamma$ is conceptually analogous to the $\alpha$ parameter in the original analysis.

In the second period, if the liberal agency chooses to accept the prevailing first-period interpretation without attempting any revision, then its second-period utility is

$$
U_{\mathrm{L}}^{\text {period2 }}(\text { accept })=-\left(1-x_{1}\right) .
$$

If, on the other hand, the liberal agency decides in the second period to incur the cost $k$ (where we now assume that $k \leq 1 / 2$ ) and revise the interpretation that was chosen in the first period $\left(x_{1}\right)$, its expected utility is

$$
\begin{aligned}
\mathrm{EU}_{\mathrm{L}}^{\text {period2 } 2}(\text { revise })= & -\left[1-\gamma\left(x_{2}-x_{1}\right)\right]\left(1-x_{2}\right) \\
& -\gamma\left(x_{2}-x_{1}\right)\left(1-x_{1}\right)-k .
\end{aligned}
$$

The liberal agency would choose $x_{2}$ to maximize its expected utility. The first order condition of expression (A2) with respect to $x_{2}$ yields

$$
x_{2}=x_{1}+\frac{1}{2 \gamma} \text {. }
$$

Recall that the $[0,1]$ interval is the policy space that the statutory 
ambiguity opens up for the agency. From expression (A3), one can see that for any $\gamma \leq 1 / 2$, the liberal agency will choose $x_{2}=1$ in the second period, because any more liberal interpretation would be outside of the permissible policy space.

The liberal agency will choose to revise the existing statutory interpretation only if the expected second-period utility from doing so is positive-that is, only if expression (A2) is greater than expression (A1). If, in expression (A3), we get $x_{2}<1$, then we can substitute expression (A3) into expression (A2). Doing so yields the result that the liberal agency will attempt to revise the interpretation of the statute if and only if

$$
\gamma k \leq \frac{1}{4}
$$

Intuitively, if the cost $k$ of revising the interpretation is low, and if $\gamma$ is also low (implying a high likelihood that the judiciary will uphold a new agency interpretation), the agency will revise the interpretation that was chosen in the first period. Note that this condition does not depend on $x_{1}$ : for any $x_{1}$ chosen in the first period, if inequality (A4) holds, then the liberal agency will choose an $x_{2}$ that is greater than $x_{1}$ by $1 / 2 \gamma$, whereas if inequality (A4) does not hold, then the liberal agency will not attempt to revise the first-period interpretation. Therefore, regardless of whether inequality (A4) holds, the conservative agency will choose $x_{1}=0$, because this will maximize its utility in either case.

So far, we have analyzed the case where expression (A3) yields $x_{2}<1$. Since we have shown that $x_{1}=0$ in this case, we know that $x_{2}<1$ in expression (A3) only when $\gamma>1 / 2$. Thus, when $\gamma>1 / 2$, the conservative agency will choose $x_{1}=0$.

Now let us turn to the case where $\gamma \leq 1 / 2$. In this case, expression (A3) implies that the liberal agency will choose $x_{2}=1$ (the agency cannot choose $x_{2}>1$, since it is outside the policy space [0,1]). So, if the liberal agency decides to revise the interpretation that was chosen in the first period $\left(x_{1}\right)$, we can substitute $x_{2}=1$ into expression (A2) to derive the liberal agency's expected utility in the second period. Doing so yields

$$
\mathrm{EU}_{\mathrm{L}}^{\text {period2}}(\text { revise })=-\gamma\left(1-x_{1}\right)^{2}-k .
$$

The liberal agency will revise the existing statutory interpretation only if the expected second-period utility from doing so is positive-that is, only if expression (A5) is greater than expression (A1). Solving this condition (which entails solving a quadratic equation) yields the result 
that the liberal agency will attempt to revise the first-period interpretation if and only if

$$
x_{1}<\frac{2 \gamma-1+\sqrt{1-4 \gamma k}}{2 \gamma} \equiv x^{T} .
$$

Thus, the value $x^{\mathrm{T}}$ is the most conservative first-period interpretation that would not trigger an attempted reversal by the liberal agency in the second period.

Now consider the conservative agency's choice. The conservative agency can lock in its interpretation for both periods if it chooses $x_{1}=x^{\mathrm{T}}$. Its total utility in that case is

$$
U_{C}(\text { lock in })=-(1+\delta) x^{T} .
$$

If the conservative agency were to choose a first-period interpretation $x_{1}<x^{\mathrm{T}}$, the liberal agency would attempt a second-period reversal by setting $x_{2}=1$. Accordingly, the conservative agency would choose $x_{1}=0$, because there is no advantage to choosing any $x_{1} \in\left(0, x^{\mathrm{T}}\right)$. The conservative agency's expected utility from this more risky choice is

$$
\mathrm{EU}_{\mathrm{C}}(\text { risky })=-\delta(1-\gamma)+\delta \beta k
$$

The conservative agency will (weakly) prefer the lock-in approach to the risky approach if

$$
x^{\mathrm{T}} \leq \frac{\delta(1-\gamma-\beta k)}{1+\delta} .
$$

Intuitively, if $x^{T}$ is close enough to the conservative agency's ideal point $\left(x_{\mathrm{C}}=0\right)$, the conservative agency will choose $x_{1}=x^{\mathrm{T}}$ over $x_{1}=0$. If we define $Z=x^{T}-[\delta(1-\gamma-\beta k) /(1+\delta)]$, we can define the conservative agency's optimal first-period interpretation, $x_{1}^{*}$, as follows:

$$
x_{1}^{*}=\left\{\begin{array}{ll}
0 & \text { if } Z>0 \\
x^{\mathrm{T}} & \text { if } Z \leq 0
\end{array} .\right.
$$

An increase in the probability that the judiciary will reject an inconsistent agency interpretation makes the optimal lock-in approach more conservative. Formally,

$$
\frac{\partial x^{\mathrm{T}}}{\partial \gamma}=\frac{\sqrt{1-4 \gamma k}-(1-2 \gamma k)}{2 \gamma^{2} \sqrt{1-4 \gamma k}}<0 .
$$

Recall, in interpreting expression (A10), that, in this case, both $\gamma$ and $k$ are less than $1 / 2$.

In contrast to the basic model presented in the main text, here $Z$ is not monotonically decreasing in $\gamma$, which complicates the analysis. How- 
ever, the same dynamics apply, and the qualitative results continue to hold. For example, suppose that $k=.5, \delta=.95$, and $\beta=0$. In this case, we can define $\gamma^{\mathrm{T}}$ as the value of $\gamma$ for which $Z=0$; for these parameters, $\gamma^{\mathrm{T}}=.42$. The conservative agency adopts the risky approach and sets $x_{1}^{*}=0$ when $\gamma<\gamma^{\mathrm{T}}$. It adopts the lock-in approach and sets $x_{1}^{*}=x^{\mathrm{T}}$ when $\gamma \in\left[\gamma^{\mathrm{T}}, 1 / 2\right]$. However, because $\partial x^{\mathrm{T}} / \partial \gamma<0$, the relationship between the level of judicial hostility to inconsistent agency interpretations $(\gamma)$ and the aggressiveness of the first-period interpretation $\left(x_{1}^{*}\right)$ is nonmonotonic, as illustrated in Figure 1 (only now, as $\gamma$ increases above $\gamma^{\mathrm{T}}$, the point at which the conservative agency reverts to setting $x_{1}^{*}=$ 0 is $\gamma=1 / 2$ ).

Thus, although the analysis is considerably more complicated, the main qualitative results of our model continue to hold when we assume $\alpha\left(\left|x_{2}-x_{1}\right|\right)=\gamma\left(x_{2}-x_{1}\right)$, rather than assuming that $\alpha$ is constant for all $x_{2}=x_{1}$. This does not mean that these results will hold for any function in which the probability of judicial reversal is an increasing function of $\left|x_{2}-x_{1}\right|$; we leave that inquiry into the generality of our results to future research. Nonetheless, the extension in this appendix demonstrates that the intuition underlying our results is robust to a larger set of assumptions about how courts react to agency interpretive inconsistency.

\section{APPENDIX B}

At $\alpha^{\mathrm{T}}$, the conservative agency's utility from the risky approach and that from the lock-in approach are equal. Therefore, using expression (7), we get

$$
\frac{(1+\delta) k}{1-\alpha^{\mathrm{T}}}=1+\delta \alpha^{\mathrm{T}}+\delta \beta k
$$

The liberal agency's utility from the conservative agency choosing the lock-in approach is defined in expression (15). We can use (B1) to define this utility at $\alpha^{T}$ :

$$
U_{\mathrm{L}}\left(\text { lock in, } \alpha^{\mathrm{T}}\right)=\frac{-(1+\delta) k}{1-\alpha^{\mathrm{T}}}=-\left(1+\delta \alpha^{\mathrm{T}}+\delta \beta k\right) \text {. }
$$

Now, we would like to find $\tilde{\alpha}^{\mathrm{T}}$ such that the liberal agency's utility from the conservative agency's choice of the risky approach when $\alpha=\tilde{\alpha}^{\mathrm{T}}$ is equal to the liberal agency's utility from the conservative agency's choice of the lock-in approach when $\alpha=\alpha^{\mathrm{T}}$ (that is, $U_{\mathrm{L}}\left[\right.$ risky, $\left.\tilde{\alpha}^{\mathrm{T}}\right]=$ $U_{\mathrm{L}}\left[\right.$ lock in, $\left.\left.\alpha^{\mathrm{T}}\right]\right)$. Therefore, using expressions (14) and (B2): 


$$
-\left(1+\delta \tilde{\alpha}^{\mathrm{T}}+k\right)=-\left(1+\delta \alpha^{\mathrm{T}}+\delta \beta k\right)
$$

or

$$
\tilde{\alpha}^{\mathrm{T}}=\alpha^{\mathrm{T}}-k \frac{(1-\delta \beta)}{\delta} .
$$

At $\alpha^{\prime} \in\left[\tilde{\alpha}^{\mathrm{T}}, \alpha^{\mathrm{T}}\right]$, the liberal agency's utility from the conservative agency choosing the risky approach is

$$
\mathrm{EU}_{\mathrm{L}}\left(\text { risky, } \alpha^{\prime}\right)=-\left(1+\delta \alpha^{\prime}+k\right) \text {. }
$$

We would like to find $\alpha^{\prime \prime}$ such that the liberal agency's utility from the conservative agency's choice of the lock-in approach when $\alpha=\alpha^{\prime \prime}$ is equal to the liberal agency's utility from the conservative agency's choice of the risky approach when $\alpha=\alpha^{\prime}$ (that is, $U_{\mathrm{L}}\left[\right.$ risky, $\left.\alpha^{\prime}\right]=$ $U_{\mathrm{L}}\left[\right.$ lock in, $\left.\left.\alpha^{\prime \prime}\right]\right)$. Accordingly,

$$
-\left(1+\delta \alpha^{\prime}+k\right)=\frac{-(1+\delta) k}{1-\alpha^{\prime \prime}}
$$

or

$$
\alpha^{\prime \prime}=1-\frac{(1+\delta) k}{1+\delta \alpha^{\prime}+k}
$$

\section{REFERENCES}

Arrow, Kenneth J. 1951. Social Choice and Individual Values. New York: John Wiley and Sons.

Beermann, Jack M. 2003. Presidential Power in Transitions. Boston University Law Review 83:947-1016.

Berry, Christopher, and Jacob E. Gersen. 2008. The Unbundled Executive. University of Chicago Law Review 75:1385-434.

$\rightarrow$ Cohen, Linda R., and Matthew L. Spitzer. 1994. Solving the Chevron Puzzle. Law and Contemporary Problems 57(2):65-110.

- 1996. Judicial Deference to Agency Action: A Rational Choice Theory and an Empirical Test. Southern California Law Review 69:431-76.

$\rightarrow$ Cross, Frank B., and Emerson H. Tiller. 1998. Judicial Partisanship and Obedience to Legal Doctrine: Whistleblowing on the Federal Courts of Appeals. Yale Law Journal 107:2155-76.

$\rightarrow$ De Figueiredo, Rui J. P., Jr. 2002. Electoral Competition, Political Uncertainty, and Policy Insulation. American Political Science Review 96:321-33.

$\rightarrow$ Diver, Colin S. 1985. Statutory Interpretation in the Administrative State. University of Pennsylvania Law Review 133:549-99. 
Dotan, Yoav. 2005. Making Consistency Consistent. Administrative Law Review 57:995-1069.

Elliott, E. Donald. 2005. Chevron Matters: How the Chevron Doctrine Redefined the Roles of Congress, Courts and Agencies in Environmental Law. Villanova Environmental Law Journal 16:1-18.

Givati, Yehonatan. 2010. Strategic Statutory Interpretation by Administrative Agencies. American Law and Economics Review 12:95-115.

$\rightarrow$ Gossett, David M. 1997. Chevron, Take Two: Deference to Revised Agencies' Interpretation of Statutes. University of Chicago Law Review 64:681-708.

$\rightarrow$ Hickman, Kristin E., and Matthew D. Krueger. 2007. In Search of the Modern Skidmore Standard. Columbia Law Review 107:1235-320.

Kaplow, Louis, and Steven Shavell. 2002. Fairness versus Welfare. Cambridge, Mass.: Harvard University Press.

Listokin, Yair. 2008. Learning through Policy Variation. Yale Law Journal 118: 480-553.

McCubbins, Matthew D., Roger G. Noll, and Barry R. Weingast. 1987. Administrative Procedures as Instruments of Political Control. Journal of Law, Economics and Organization 3:243-77.

$\rightarrow$ - 1989. Structure and Process, Politics and Policy: Administrative Arrangements and the Political Control of Agencies. Virginia Law Review 75: 431-82.

Mendelson, Nina A. 2003. Agency Burrowing: Entrenching Policies and Personnel before a New President Arrives. New York University Law Review 78:557-666.

Merrill, Thomas W. 1992. Judicial Deference to Executive Precedent. Yale Law Journal 101:969-1041.

Miles, Thomas J., and Cass R. Sunstein. 2006. Do Judges Make Regulatory Policy? An Empirical Investigation of Chevron. University of Chicago Law Review 73:823-81.

Moe, Terry M. 1989. The Politics of Bureaucratic Structure. Pp. 267-330 in Can the Government Govern?, edited by John E. Chubb and Paul E. Peterson. Washington, D.C.: Brookings.

- 1990. The Politics of Structural Choice: Towards a Theory of Public Bureaucracy. Pp. 116-53 in Organization Theory: From Chester Barnard to the Present and Beyond, edited by Oliver E. Williamson. Berkeley, Calif.: University of California Press.

Murphy, Richard W. 2005. Judicial Deference, Agency Commitment, and Force of Law. Ohio State Law Journal 66:1013-74.

O’Connell, Anne Joseph. 2008. Political Cycles of Rulemaking: An Empirical Portrait of the Modern Administrative State. Virginia Law Review 94:889986.

Pierce, Richard J., Jr. 1988. Chevron and Its Aftermath: Judicial Review of 
Agency Interpretations of Statutory Provisions. Vanderbilt Law Review 41: 301-14.

$\rightarrow$ Revesz, Richard L. 1997. Environmental Regulation, Ideology, and the D.C. Circuit. Virginia Law Review 83:1717-72.

$\rightarrow$ Richards, Mark J., Joseph L. Smith, and Herbert M. Kritzer. 2006. Does Chevron Matter? Law \& Policy 28:444-69.

Riker, William H. 1982. Liberalism against Populism: A Confrontation between the Theory of Democracy and the Theory of Social Choice. San Francisco, Calif.: W.H. Freeman \& Co.

Scalia, Antonin. 1989. Judicial Deference to Administrative Interpretation of Law. Duke Law Journal 1989:511-21.

$\rightarrow$ Shepsle, Kenneth A. 1992. Congress Is a "They," Not an "It": Legislative Intent as Oxymoron. International Review of Law and Economics 12:239-56.

Shuren, Jeffrey E. 2001. The Modern Regulatory Administrative State: A Response to Changing Circumstances. Harvard Journal on Legislation 38:291329.

$\rightarrow$ Smith, Joseph L. 2007. Presidents, Justices, and Deference to Administrative Action. Journal of Law, Economics \& Organization 23:346-64.

$\rightarrow$ Spiller, Pablo T. 1992. Agency Discretion under Judicial Review. Mathematical and Computer Modelling 16(8/9):185-200.

$\rightarrow$ Stephenson, Matthew C. 2003. "When the Devil Turns. . ": The Political Foundations of Independent Judicial Review. Journal of Legal Studies 32:59-89.

- 2004. Mixed Signals: Reconsidering the Political Economy of Judicial Deference to Administrative Agencies. Administrative Law Review 56:657738.

$\rightarrow$ - 2006a. Legislative Allocation of Delegated Power: Uncertainty, Risk, and the Choice between Agencies and Courts. Harvard Law Review 119: 1035-70.

$\rightarrow$ - 2006b. The Strategic Substitution Effect: Textual Plausibility, Procedural Formality, and Judicial Review of Agency Statutory Interpretations. Harvard Law Review 120:528-72.

- 2008. Optimal Political Control of the Bureaucracy. Michigan Law Review 107:53-110.

$\rightarrow$ Stephenson, Matthew C., and Adrian Vermeule. 2009. Chevron Has Only One Step. Virginia Law Review 95:597-609.

Stiglitz, Joseph E. 2000. Economics of the Public Sector. 3rd Ed. New York: W. W. Norton \& Co.

$\rightarrow$ Sunstein, Cass R. 1990. Law and Administration after Chevron. Columbia Law Review 90:2071-120.

Weaver, Russell L. 1992. A Foolish Consistency Is the Hobgoblin of Little Minds. Baylor Law Review 44:529-67. 